\title{
Determination of the Cost of Training of Undergraduate Medical (MBBS) Student at All India Institute of Medical Sciences, New Delhi, India
}

\author{
${ }^{1}$ Rakesh Verma, ${ }^{2}$ Shakti Kumar Gupta, ${ }^{3}$ Sidhartha Satpathy, ${ }^{4}$ Sunil Kant, ${ }^{5}$ Sunil Chumber, ${ }^{6}$ RC Deka
}

Keywords: Costing, Undergraduate study, AlIMS, Computation of academics.

How to cite this article: Verma R, Gupta SK, Satpathy S, Kant S, Chumber S, Deka RC. Determination of the Cost of Training of Undergraduate Medical (MBBS) Student at All India Institute of Medical Sciences, New Delhi, India. Int J Res Foundation Hosp Healthc Adm 2013;1(1):1-7.

Source of support: Nil

Conflict of interest: None

\section{INTRODUCTION}

All India Institute of Medical Sciences (AIIMS), New Delhi, is a unique institution and one its kind in India. It was established in the year 1956 by an Act of Parliament of India as an autonomous institute of national importance. The act mandates that 'the Institute shall be a body corporate by the name aforesaid having perpetual succession and a common seal, with power to acquire, have and dispose-of property, both movable and immovable, and to contract, and shall by the said name sue and be sued'.

The objectives ${ }^{1}$ of the institute are to develop patterns of teaching in undergraduate and postgraduate medical education in all the branches of medicine so as to demonstrate highest standards of medical education in India. Accordingly, the Institute focuses on the trinity of objectives of training, research and patient care, with training being the foremost of all. It is this trinity of mission that guides all the endeavors undertaken in the institute. The primary objectives of the institute are teaching and research. Since these cannot exist

\footnotetext{
${ }^{1}$ Commanding Officer, ${ }^{2} \mathrm{Head},{ }^{3,5}$ Professor,

${ }^{4}$ Dy DGAFMS (Coord), ${ }^{6}$ Professor, Director and CEO

${ }^{1}$ Armed Forces Medical Services, India

${ }^{2,3}$ Department of Hospital Administration, All India Institute of Medical Sciences, New Delhi, India

${ }^{4}$ Office of DGAFMS, Ministry of Defence, New Delhi, India

${ }^{5}$ Department of Surgery, All India Institute of Medical Sciences New Delhi, India

${ }^{6}$ All India Institute of Medical Sciences, New Delhi, India

Corresponding Author: Col Rakesh Verma, Commanding Officer, 410 Fd Hospital, C/o 56, APO, e-mail: dr.rakeshverma@ gmail.com
}

without patient care, the patient care exists as means to these objectives. The institute runs a number of training courses in medical, paramedical and nursing fields and trains a vast pool of experts who become part of the healthcare personnel resource of the country.

Undergraduate training has, since the very beginning, received special attention in the Institute. The undergraduate program Bachelor of Medicine and Bachelor of Surgery (MBBS) has an intake of 50 students out of which five students come as sponsored candidates from foreign countries.

\section{Need for the Study}

The conduct of the undergraduate course at AIIMS comes for a cost. Training, being first of the trinity, takes precedence and as a result the training infrastructure has been created with lot of care and eye for detail. Resources are utilized in maintaining these facilities, paying the faculty and staff and maintaining the boarding and lodging services for students. These resource-limited times demand costconsciousness in all endeavors and, therefore, cost awareness and subsequent cost containment has become a compelling reality. The instant study is relevant in this context. The precise costing has the potential to influence the decision making regarding the course conduct, content and the outcomes. It can transform our understanding of the costs of various training processes and contents. This study of costing of undergraduate program (MBBS course) at AIIMS will augment a range of activities of funding, budgeting and accounting for the conduct of the MBBS course.

\section{REVIEW OF LITERATURE}

The subject of cost of instruction is sometimes overlooked in the broader context of discussions about affordability, cost, price, and the economics and finance of higher education. $^{2}$ There is, however, a distinct though relatively small knowledge base of literature and research about cost of instruction.

There are several characteristics of higher education institutions. These are as follows:

- The accounting systems of large higher education institutions may produce a plethora of periodic reports, like the budgets and related financial documents which 
are likely to be understood only by budgeting and accounting officers but not by senior academic officials.

- The outputs of faculty - the key employees-are interrelated and not clearly separable from each other. There are no obvious ways to distinguish between faculty research, teaching and professional service.

- The distinctions between inputs and outputs and producers and consumers may be equally blurred.

- The costs and revenues of higher education institutions may be integrally related and certain costs may not be incurred unless they were to be explicitly funded from outside sources. For example, universities carry out certain research projects only if independently funded.

- The capacity constraints of higher education institutions are not clearly discernable. Faculty, e.g. does not work a standard number of hours per week and hence can undertake additional assignments without any readily apparent reduction in the time devoted to other assignments. Similarly, new programs and activities can be added without any obvious sacrifice in the quantity or quality of existing ones. At the same time, capacity costs are proportionately high. Classrooms, laboratories and dormitories are subject to long planning, approval and construction processes and it often takes at least two or more years before new faculty positions can be approved and filled.

\section{Costing Studies of Undergraduate Medical Education}

In case of training of doctors, the costs assume accentuated importance. The reasons for this are two fold. Firstly, there has been general concern about the rising costs of medical education, especially at the undergraduate level. Secondly, the costs have direct impact on the quality of medical education and, therefore, the quality of future doctors.

These concerns are not new. In 1929, WH Hattie ${ }^{3}$ expressed that the cost of medical education has already become very great. More recently in the year 1986, MT Rabkin ${ }^{4}$, Professor of Medicine at Harvard Medical School commented about reducing the cost of medical education. He argued that for 'cost effectiveness in medical educationwe have only begun to make serious inquiry, and there is no obvious solution in the wings.'

Jean D Gray and John Ruedy, in a paper titled 'Undergraduate and Postgraduate Medical Education in Canada ${ }^{5}$ presented at the Trilateral Physician Workforce Conference held in Washington in November, 1996, stated that until recently, costs of medical education have been very reasonable in Canada. However, since the early 1990s, tuition fees have risen, the costs of credentialing and examinations have increased, malpractice insurance and licensing fees have become higher and obtaining an appropriate residency training position has become more costly.
William J Bicknell, Andrew C Beggs and Phi Van Tham published a landmark article 'Determining the Full Costs of Medical Education in Vietnam: Results, Policy Implications and a Generalizable Model ${ }^{6}{ }^{6}$ in Health Policy and Planning (2001). They described the methodology for computing total costs of teaching undergraduate medical students at Thai Binh Medical School, Vietnam. The model for computation of costs was a full-cost model. The study also considers faculty and staff contact hours as the primary cost driver at Thai Binh Medical School. This was done using a top-down costing approach, i.e. the fund provisions were examined and the allocations were done based upon '6-year medical student equivalents'. This 6-year medical student equivalents was a novel concept and was developed to isolate the training of undergraduate medical students from all other trainings so that costs can be isolated and computed.

Several such studies have also been carried out across the globe. The notable ones among these are Vimolket T $(2003)^{7}$, Morrison G (2005) ${ }^{8}$, Jones and Korn (1997) ${ }^{9}$. Three closely related reports from Australia (Andrew, $1976^{10}$; Andrew and Nehrmann, $1977^{11}$ ) and the US (Mulhausen et al $1989^{12}$ ) consider the cost impact of medical student teaching on the overall costs of teaching hospitals.

The overarching feature of the methodologies in these studies was an emphasis on determining, through analysis of the curriculum, the proportion of faculty hours dedicated to teaching medical students. One study expressly stated that 'all data were based on faculty contact hours, the primary driver of cost' (Rein et al 1997). ${ }^{13}$

In the Indian context, the earliest efforts to cost undergraduate medical education were made by Prabha Ramalingaswami ${ }^{14}$ of Jawaharlal Nehru University, New Delhi, in the year 1984. This was published in the Indian Journal of Medical Education (May-Aug 1984). In this study, carried out in 14 medical colleges across India, only recurring costs of the medical colleges were taken into account while working out the costs per student. The study methodology comprised of record reviews, interviews with the faculty in one medical college to develop assumptions about the teaching. A questionnaire was also used. The institutional costs (capital and recurring) were analyzed separately.

The Tata Consultancy Services, New Delhi (TCS), carried out a study ${ }^{15}$ in 1987 at AIIMS to determine the costs of services rendered by the institute to public and to highlight any department or service consuming resources heavily in the short or long run. The study worked out the unit costs of various services. It also proposed a costing model for implementation at the institute. The study also computed the costs of teaching undergraduate and postgraduate students. 
The costs of one student was worked out as ₹ $1,06,570 /$ annually.

In 2000, Lt Col Punit Yadav carried out a study (unpublished dissertation) to compute the costs of training of undergraduate student at Graduate Wing of Armed Forces Medical College, Pune, India. A mix of traditional and activity-based costing methodology was used. ${ }^{16}$ The study computed the costs of one undergraduate student as ₹ $10,12,437.24$.

Common theme in the literature is the difficulty in determining how much of the work in the clinical faculty can reasonably be ascribed to the medical education function (Goodwin, Gleason and Kontos 1997'17; Rein et al 1997 and also Prabha Ramalingaswami 1984). The problem is that much of the clinical work that is performed at a teaching hospital serves both a patient care function and an educational function. Rein et al express it eloquently: 'Although it is, indeed, a wonderful aspect of medical education that both can be accomplished at the same time, for purposes of accounting it is necessary to try to assign the fraction of the time attributable to each endeavor separately'. Clearly, the most reasonable way to make this type of determination is to engage the teaching staff in a conversation about their work. They are the best judges of what work they perform on a day-to-day basis. Also, if the staff is involved in developing the assumptions underlying the model, they will be much more likely to accept the results of such a costing study.

\section{METHODOLOGY}

The study was carried out form July 2007 to June 2008 at the AIIMS, New Delhi. The study is based upon classifying costs, identifying cost centers and tracing the costs to the MBBS training. Cost allocation to the relevant cost center was done by apportioning the costs in the proportion of MBBS students.

In the first stage, the inputs collected were curriculum of the MBBS course, detailed information about the training activities concerning MBBS students, weekly schedule of training programs and such similar information. The information thus obtained was compiled, tabulated and analyzed. Further, the information about the norms for the faculty and the residents as relevant to the training of MBBS graduates were collected and tabulated. The later was done to obtain the minimum faculty and residents requirements for the conduct of MBBS course at AIIMS. The information about each department, center and facility was computed to obtain the direct, indirect and the total costs incurred toward the MBBS training for a student. In the second stage, the costs information was utilized to carryout the traditional costing by tracing the costs to the cost centers and finding out the cost drivers. Time driven activity-based costing was done using the same information and then a comparison was drawn to estimate the realistic costs incurred toward the MBBS graduate in AIIMS. In the third stage, an attempt was made to formulate a costing model for computing the costs incurred in training of a MBBS student.

Costing has been done for the entire duration of the course, i.e. from the day, the MBBS course begins up till the completion of compulsory internship. The study included only the costs incurred by the institute on education and other related activities.

The manner in which costs for various resources was considered is given in Table 1.

\section{Data Collection, Tabulation and Computation}

The cost information was collected from each department and facilities. Only the departments as per the norms of Academic Committee of AIIMS were included. Data was collected by inspection and review of records, perusal of policies and rules/regulations of AIIMS and various other government departments and ministries and inputs from key informants.

Key-informants from the non-teaching departments/ sections were the heads of the respective department/ section. From teaching departments, the faculty in-charge for teaching of undergraduate MBBS students was identified. In many cases, other faculty members whose inputs were felt necessary were also contacted. These faculty members were identified in consultation with the respective heads of the department and the faculty in-charge undergraduate teaching.

Data was tabulated and compiled using OpenOffice Calc. All costs were annualized and then utilized for computation of the results. Cost computation was done using two methods. First, using traditional costing method, second by using time driven activity-based costing ${ }^{20}$ method.

A few exclusions were identified $a b$ initio. These are as follows:

- It has been assumed thet all students progress to next semester without failures.

- Air conditioning: Eighty percent of all floor space has been counted as under air conditioning.

- Personal costs like costs toward food, books, stationery, etc. excluded.

- Costs on account of delay in completion of the course excluded.

- Only the significant costs have been included, others have been excluded, e.g. the value of fee charged from MBBS students has been excluded being relatively small amount.

- The costs toward Employee Health Scheme were excluded since there are (a) large variety of beneficiaries including serving, retired staff (b) no pattern can be 


\begin{tabular}{|c|c|}
\hline Resource & Manner of consideration for costing \\
\hline Land & $\begin{array}{l}\text { - The value of the land has been ignored. } \\
\text { - If included, would unduly influence the total costs of training making it a biased observation. }\end{array}$ \\
\hline Buildings & $\begin{array}{l}\text { - The rental rate of Directorate of Estates, Ministry of Urban Development Government of India has been used for } \\
\text { costing as this is the basis for cost recovery from the users. }\end{array}$ \\
\hline $\begin{array}{l}\text { Equipment, } \\
\text { furniture and } \\
\text { fixtures }\end{array}$ & $\begin{array}{l}\text { - The replacement values, i.e. the current values have been taken in to consideration for computing the costs. } \\
\text { Where only historical costs were available, these were adjusted for the year } 2007 \text { using the Linked All India (Urban } \\
\text { Non-Manual Employees) Consumer Price Index. }{ }^{18} \text { The index for } 2007 \text { is } 503 \text { on base as } 100 \text { for the year } 1984 \text { and } \\
1985 .\end{array}$ \\
\hline Personnel & $\begin{array}{l}\text { - The 'Costs to the company' data, i.e. total costs to the institute were computed including the salaries, allowances, } \\
\text { perks and other facilities computed at mid-point of the pay scale for the year } 2007 \text {. } \\
\text { - In case of personal staff like principal private secretaries, private secretaries, personal assistants and orderlies/ } \\
\text { peons, the costs have been built-in into the costs incurred on the categories of senior staff members who are } \\
\text { entitled for using the services of these staff. }\end{array}$ \\
\hline Library & $\begin{array}{l}\text { - The average expenditure per year was computed using available data on 'plan' and 'non-plan' allocations of past } \\
\text { 3-years. }\end{array}$ \\
\hline $\begin{array}{l}\text { Supplies/ } \\
\text { consumables }\end{array}$ & $\begin{array}{l}\text { The supplies and consumables are procured by the respective departments and facilities using the funds from } \\
\text { the non-plan head of the budget allocated to each department/facility. } \\
\text { - The average of the non-plan outlay of past three financial years has been taken toward all the consumables and } \\
\text { supplies of respective department. These costs are then apportioned appropriately. }\end{array}$ \\
\hline Utilities & $\begin{array}{l}\text { - Electricity-average actual expenditure on electricity. } \\
\text { - Water-a consumption of } 200 \text { liter per person }{ }^{19} \text { has been taken for water usage and costs have been calculated. } \\
\text { - Air conditioning-installation costs have been included and distributed over the estimated life of the AC plant. } \\
\text { The maintenance costs have been taken at } 5 \% \text { of installation costs annually. }\end{array}$ \\
\hline Expenses & $\begin{array}{l}\text { - This includes stipend to interns and scholarships to meritorious MBBS students. } \\
\text { - The actual expenditure has been included. }\end{array}$ \\
\hline
\end{tabular}

deciphered in the expenditure as it dependent largely upon the type of illnesses treated, (c) the costs are spread over several cost centers, like pharmacy, wards, hospital stores, etc. and (d) no separate accounting is done for serving and retired staff.

- Costs of general administration.

\section{Costing}

The study has been carried out with the objective of finding out the costs incurred on training of undergraduate MBBS student at AIIMS by using two distinct approaches to costing namely - traditional costing and time driven activity-based costing. The summary of the costs worked out by these two methods is given below:

\section{Traditional Costing Steps}

1. Curriculum analysis

2. Determine the 'MBBS student equivalent'.

3. Costs computation, apportionment and assignment

4. Computation of costs of one MBBS student at AIIMS. The curriculum analysis of MBBS course and other courses in AIIMS was carried out to ascertain the quantum of resources consumed by the MBBS course. Since the resource use is mixed and no separate accounting is done for resources consumed by MBBS, the quantum consumed by MBBS students was ascertained by determining 'MBBS Student Equivalent'. To explain the concept, e.g. if one student of MBBS course consumes 'one unit' of a given resource, how much of the resource would be required to train the students other than MBBS students?

In order to get this equivalent, discussion were held with the Dean (academics), Sub-dean (academic) and the other key-informants at the institute and the estimation is based upon their judgments. The postgraduate and postdoctoral students have been taken at par with each other since the resource consumption is comparable. The annual number of admission of MBBS students is 50 and postgraduate and postdoctoral students are 291. As far as other undergraduate courses (like nursing and paramedical) are concerned, these do not overlap significantly with MBBS course in terms of resource consumption and, therefore, have been excluded from consideration.

It has been determined that training of a postgraduate student consumes 2.5 times the resources as compared to MBBS student annually. Utilizing this equivalent, a weighted percentage of the MBBS students has been calculated. As Table 2 indicates, in terms of medical school resource consumption, MBBS students account for about $11.2 \%$ of all the students at AIIMS.

The summary of the costs worked out by the traditional costing method is given in Table 3 .

The annual direct and indirect costs per student come to ₹ 17.47 lacs and ₹ 13.84 lacs respectively. The total per student annual and per course costs is ₹ 31.31 lacs and ₹ 172.20 lacs respectively. 
Determination of the Cost of Training of Undergraduate Medical (MBBS) Student at All India Institute of Medical Sciences

\begin{tabular}{lllllll}
\hline \multicolumn{7}{c}{ Table 2: MBBS student equivalent computation } \\
\hline S. no. & Course & No. of students & Duration of course & Equivalents & Total equivalents & $\%$ in equivalent terms \\
\hline 1. & MBBS & 50 & 5.5 years & 1 & $1 \times 5.5 \times 50=275$ & $11.2 \%$ \\
2. & PG courses & 291 & 3.0 years & 2.5 & $2.5 \times 3 \times 291=2183$ & $88.8 \%$ \\
\hline & & & & Total & 2458 & $100 \%$ \\
\hline
\end{tabular}

Table 3: Summary of costs by traditional costing

\begin{tabular}{|c|c|c|c|c|}
\hline \multirow[t]{2}{*}{ S. no. } & \multirow[t]{2}{*}{ Resource } & \multicolumn{2}{|c|}{ Annual per batch costs (₹ lacs) } & \multirow[t]{2}{*}{ Cost assignment method } \\
\hline & & Direct & Indirect & \\
\hline 1. & Personnel_faculty & 357 & & Apportioned \\
\hline 2. & Personnel-NTS & & 589 & Traced \\
\hline 3. & Hospital costs & 345 & & Apportioned \\
\hline 4. & Material—buildings & & 10.09 & Apportioned \\
\hline 5. & Material_furniture & & 4.44 & Apportioned \\
\hline 6. & Material-utilities & & 59.17 & Apportioned \\
\hline 7. & Material—equipment & 131.95 & & Traced \\
\hline 8. & Material-library & 4.80 & & Apportioned \\
\hline 9. & Material-transport & & 3.64 & Traced \\
\hline 10. & Material_acad Office & & 0.55 & Traced \\
\hline 11. & Material—CMET & & 1.32 & Traced \\
\hline 12. & Money—non-plan allocation & & 24.19 & Apportioned \\
\hline 13. & Money-stipend & 34.29 & & Traced \\
\hline \multirow[t]{6}{*}{14.} & Money_scholarships & 0.513 & & Traced \\
\hline & Annual costs for one batch of 50 students & 873.55 & 692.40 & \\
\hline & Annual per student costs & 17.47 & 13.84 & \\
\hline & Per student per year cost & 31.31 & & \\
\hline & Total costs of MBBS course & 172.20 & & \\
\hline & & & & NTS_-nonteaching sta \\
\hline
\end{tabular}

Table 4: Summary of costs as per TD-ABC for the entire duration (5.5 years) of MBBS course

\begin{tabular}{|c|c|c|c|c|c|}
\hline S. no. & Resource & Costing method & Unit cost (₹) & $\begin{array}{c}\text { Usage time } \\
\text { (hours) }\end{array}$ & $\begin{array}{l}\text { Total cost } \\
\text { (₹) }\end{array}$ \\
\hline \multirow[t]{2}{*}{1.} & Personnel_faculty & TD-ABC & - & - & 2047089 \\
\hline & Personnel-NTS \$ & TD-ABC & - & - & 5859856 \\
\hline 2. & Material—hospital & TD-ABC & 128416.21 & $3150^{\#}$ & 404511061.5 \\
\hline 3. & Material—institute buildings & TD-ABC & 3495.54 & 6253 & 21857611.62 \\
\hline 4. & Material—hostel $\left.\right|^{\wedge \wedge}$ & Used as such & 70200 & - & 386100.00 \\
\hline 5. & Material_furniture & TD-ABC & 1652.44 & 6253 & 10332707.32 \\
\hline 6. & Material—utilities & TD-ABC & 2567.48 & 6253 & 15416208.73 \\
\hline 7. & Material—equipment & TD-ABC & - & - & 11162904.17 \\
\hline 8. & Material-library $\wedge^{\wedge}$ & Used as such & 479000 & & 2640000.00 \\
\hline 9. & Material-transport ${ }^{\wedge \wedge}$ & Used as such & 364000 & - & 2002000.00 \\
\hline 10. & Material—acad Office ${ }^{\wedge \wedge}$ & Used as such & 55000 & - & 302500.00 \\
\hline 11. & Material- $\mathrm{CMET}^{\wedge \wedge}$ & Used as such & 132000 & - & 726000.00 \\
\hline 12. & Money—non-plan fund ${ }^{\wedge}$ & Used as such & 2419000 & - & 13304500.00 \\
\hline 13. & Money—stipend & Used as such & - & - & 3429000.00 \\
\hline \multirow[t]{2}{*}{14.} & Money_scholarships & Used as such & - & - & 51250.00 \\
\hline & & Total costs for or & & & 494028788.34 \\
\hline
\end{tabular}

\#: The hours of training in hospital worked out from the teaching program; $\$$ : Nonteaching staff; $\wedge$ : Annual costs worked out and used as such in proportion to the MBBS Student Equivalent, since it is not feasible to determine consumed capacity of these resources

\section{Time Driven Activity-based Costing}

The time driven activity-based costing (TD-ABC) methodology steps are as follows:

1. The unit costs of supplying capacity, i.e. the resources

2. The consumption of capacity (unit times) by the activities carried out in the training of MBBS students.

The costs using TD-ABC method are as in Table 4.

Total costs for one batch of 50 students for the entire course are ₹ 4940.28 lacs and per student costs are ₹ 98.80 lacs per course.

\section{Costing Model for Costing Medical Education}

In an institute of the nature and stature like AIIMS, invariably the research and patient care would be intermingled with training. An institute at the tertiary level and higher, the training at undergraduate level may also get influenced by other activities that would invariably happen within the same environment. As a result, the undergraduate students also benefit from learning. In such institutions, it would be difficult to ascertain the costs incurred toward a particular course. Therefore, the 
following approach to costing at undergraduate students' level is proposed.

a. Firstly, all resources that are utilized for training for a course be isolated from the overall resources of the institute. Care has to be exercised that the research and service elements are suitable excluded. The unit costs of each of the resource then to be worked out.

b. Secondly, the curriculum is to be closely examined for working out the time duration of training in each subject/ department. The time spent in support and supervision activities (e.g. academic section, etc.) should be suitably worked out.

c. The total costs of consumption of the resources can be worked out by multiplying the unit costs with the time duration of consumption of each resource.

d. Certain resources which are not amenable to unit costing in terms of time (like money spent on scholarships, etc.) should be accounted on annual basis and assigned to costs objects as such.

e. For resources where segregation is not feasible (such as library), determining student equivalent for the course being costed would provide estimated resource consumption. This proportion then be used for computations.

\section{CONCLUSION}

The cost per student worked out by the two methods for one student for the entire duration of the course is shown in Table 5 below.

Table 5: Comparison of two costing methods

\begin{tabular}{ll}
\hline $\begin{array}{l}\text { Traditional costing } \\
\text { (₹ lacs) }\end{array}$ & $\begin{array}{l}\text { Time driven activity-based } \\
\text { costing (₹ lacs) }\end{array}$ \\
\hline 172.20 lacs & 98.80 lacs \\
\hline
\end{tabular}

The costing methods take into account all the resources. The costs of these resources are fully attributed to the cost objects (MBBS course in the study) in traditional costing irrespective of the utilization of the resource toward the cost object. In effect, traditional costing reflects resource costs as these resources are provided and maintained irrespective of consumption.

Similarly, the time driven activity-based costing model also accounts for all the resources consumed toward training. In this method, however, the consumption of resources is considered and costed. When the resource consumption is examined in terms of hours, it generates information about unit costs and unit times. Therefore, the difference in the two methods of costing will show the idle capacity. As is evident from the two methodologies in this study, the two methods lead to different results. This is because of the way these two methods handle the costs. The difference is really in the indirect costs which have been measured to be substantially low in activity-based costing method.

The academic courses in an institute are designed around a set of norms for staffing, space and other requisite infrastructure. These also define the minimum acceptable level below which a given course of instruction would not be held at all. The time driven activity-based costing focuses on consumed resources. While the traditional costing method focuses on the provisioned resources. Since all provisioned resources could never be used at all times; the costs computed by TD-ABC method will always be lower than the traditional costing method. It may also be a pointer to consider framing of more realistic norms.

The study computed costs incurred on MBBS students at AIIMS during the year 2007. The current costs are likely to be higher.

\section{REFERENCES}

1. All India Institute of Medical Sciences. Introduction. (Online) Available from URL: http:/www.aiims.edu/aiims/aboutaiims/ aboutaiimsintro.htm (accessed on 20 August 2007).

2. Jenny, Hans H. Cost Accounting in Higher Education: Simplified Macro- and Micro-Costing Techniques. Washington, DC: National Association of College and University Business Officers; 1996.

3. Hattie WH. Cost of Medical Education. Can Med Assoc J 1929 December 21(6):713-714.

4. Rabkin MT. Reducing the Cost of Medical Education. Health Affairs. Fall 1986;5(3):97-104.

5. Gray JD, Ruedy J. 'Undergraduate and Postgraduate Medical Education in Canada' presented at the Trilateral Physician Workforce Conference held in Washington 1996 Nov 1-3.

6. Bicknell WJ, Beggs AC, Tham PV. Determining the Full Costs of Medical Education in Vietnam: Results, Policy Implications and a Generalizable Model. Health Policy and Planning 2001; 16(4):412-420.

7. Vimolket $T$, Kamol RP, Indaratna. Cost of producing a medical doctor at Chulalongkorn University; Chot Mai Het Thang Phaet (ISSN 0125-2208). 2003;86(1):82-92.

8. Morrison G. Mortgaging Our Future-The Cost of Medical Education. N Engl J Med 2005 January;352(2):117-119.

9. Jones R, Korn D. On the Cost of Educating a Medical Student. Acad Med 1997;72(3):200-210.

10. Andrew R. Hospital Staffing and Hospital Costs. The Med J Australia 1976;2:222.

11. Andrew R, Nehrmann M. Hospital Costs - The Medical Student Component. The Med J Australia 1977;1(22):823-826.

12. Mulhausen R, Kaemmerer C, Foley J, Schultz A. Education Costs in Two Public Teaching Hospitals. Acad Med 1989:314-319.

13. Rein M, Randolph W, Short J, Coolidge K, Coates M, Carey R. Defining the Cost of Educating Undergraduate Medical Students at the University of Virginia. Acad Med 1997;72(3):218-227.

14. Prabha R. Estimation of cost of Medical Education in India. Indian Journal of Medical Education 1984 May-Aug;23(1):69-90. 
15. Developing Cost Accounting System for AIIMS. Tata Consultancy Services, Cost Accounting System, New Delhi, 1987 August.

16. Yadav P. To determine the per student cost incurred for a MBBS student of Armed Forces Medical College, Pune [dissertation]. University of Pune; 2000 December.

17. Goodwin M, Gleason W, Kontos H. A Pilot Study of the Cost of Educating Undergraduate Medical Students at Virginia Commonwealth University. Acad Med 1997;72(3): 211-217.
18. Central Statistical Organization, Ministry of Statistics \& Programme Implementation, Govt of India Memorandum No. M-12011/2/2005 - PCL dated 21 July 2008.

19. Park K. Park's Text Book of Preventive and Social Medicine. Jabalpur, India. Banarsidas Bhanot. 19th ed; 2007 February; $567 \mathrm{p}$.

20. Kaplan R, Anderson S. Time driven Activity-based Costing (Working Paper), 2004. Available at: http://www.hbs.edu/ research/facpubs/workingpapers/papers2/0304/04-045.pdf (accessed on 16 Jun 2008). 